\title{
Organizational Context on Workplace Incivility and Turnover Intention
}

\author{
DWI NOVITASARI ${ }^{1 *}$, ASRI LAKSMI RIANI ${ }^{2}$, JOKO SUYONO $^{3}$, MUGI HARSONO $^{4}$ \\ Institute of Economic Science Widya Wiwaha, Yogyakarta \\ Business and Economics Faculty \\ Sebelas Maret University \\ Surakarta, Central Java \\ INDONESIA
}

\begin{abstract}
This study aims to investigate and analyze the role of organizational context on workplace incivility and turnover intention. The research sample was 120 employees who work at the company engaged in the service industry. Multiple regression analysis was used to test the research hypotheses. The results found that organizational context influences workplace incivility, which in turn increases turnover intention. As a consequence, it is important for the organization to enhance alertness towards the occurrence of the employees' workplace incivility. Internalization and implementation of values of the organizational context can be utilized to manage employees' work performance.
\end{abstract}

Key-Words: - organizational context, management philosophy, organizational culture, workplace incivility, turnover intention.

Received: November 2, 2020. Revised: May 3, 2020. Accepted: May 7, 2020. Published: May 11, 2020.

\section{Introduction}

Behaviors most likely occurring in an organization are generally divided into two categories: positive behavior and deviant behavior. Deviant behavior includes sabotage, theft, incivility, fraud, concealment of information that should be disclosed as well as abuse of property and facilities.

Positive behavior is manifested in loyalty, a strong sense of belonging to the organization and pride as the member of the organization [1]-[3].

Incivility is a deviant behavior, which is unnoticeable and subtle, but commonly occurs in the workplace [4]. Some literatures have revealed that workplace incivility is prevalent in almost all organizations. In fact, $62 \%$ of employees reported to have experienced workplace incivility and $99 \%$ have witnessed it [5], [6].

Incivility arises due to interactions between individuals, workgroups called workgroup incivility and organizations called organizational incivility. Incivility can be viewed from two different perspectives: instigated and witnessed workplace incivility. Incivility perpetrators can originate from within the organization such as co-workers and employers and from outside the organization including customers and families.

Types of incivility are closely related to the changes in information technology, which require the organization to adapt with the automation and utilization of electronic media. This situation can give rise to cyber incivility.

Cyber incivility can be manifested in the use of harsh words in emails as well as in chats and status updates on social media. Other examples are stalking someone's personal account, posting immoral contents and spreading rumors [7]-[14].

Studies in the area of incivility have found the antecedents and outcomes of incivility. Previous studies have suggested the antecedents of incivility include organizational context, leader-member exchange, negative feedback and sadistic behavior [15]-[17]. Some previous studies also show that the leadership style that is transformational leadership is the antecedent of workplace incivility [18]-[20]. The context of transformational leaders is leaders who work with a balanced approach. Transformational leaders help and teach you how to solve the problem at hand. Transformational leadership utilizes the ability of individuals to be able to grow the potential for leadership in others [21].

However, little research has been conducted on the antecedents of incivility based on the aspects of organizational context such as management philosophy and organizational culture. According to Estes \& Wang [22], management philosophy and organizational culture affect incivility. Workplace incivility can give rise to passive and active responses. Passive responses mostly include avoidance of situation/moving on a nd negative 
feelings/stress. On the other hand, the most common positive responses are discussion/mediation, reports and employment termination [23].

Previous research found that incivility outcome is closely related with job satisfaction, turnover intention, counterproductive work behaviors (CWB), stress, burnout, service innovative behavior, knowledge-hiding behavior and job search behavior [24]-[28].

Novelty of this study focuses on management philosophy and organizational culture as organizational context based on c onceptual studies from Estes \& Wang [22]. Little empirical studies have been conducted to examine and analyze management philosophy and organizational behavior to workplace incivility. The aspects of organizational context commonly discussed in studies are job insecurity, organizational chaos, leadership, organization size, social support and job demands [29], [30].

\section{Literature Review}

Context is defined as a set of circumstances or conditions that surround a phenomenon such as a fact, process or entity. Besides, context exists in a particular phenomenon as a unit of analysis being studied. Context can explain the most prominent aspects of a phenomenon such as the characteristics of organizational setting, individual's roles in the organization and environmental factors that shape responses. Contextual variables widely used by researchers include task characteristics, organizational structure, technology, age and the size of the organization [31]-[33]. Other contextual variables are management processes, organizational culture, organizational systems, strategies, accepted norms, power, job insecurity and organizational supports [34], [35].

Incivility is categorized as mistreatment behavior with low intensity and ambiguous intention to harm the target. Incivility is a behavior that violates the norms for mutual respect [4].

Incivility is a rude and disrespectful behavior. Researches on incivility have so far been conducted to examine the interactions between employees. Incivility perpetrators can come from interpersonal interactions within the organization. Employees can turn into incivility perpetrators towards their colleagues. Thus, incivility can be defined as a deviant behavior that has low intensity committed by an employee with an ambiguous intention to harm co-workers in that norms for mutual respect and politeness are violated [36]-[38].

Turnover intention is the employees' permanent movement that is beyond the organizational boundaries or awareness and employees' intention to leave the organization [39], [40]. Turnover intention refers to three elements: the thought of quitting a job, the plan to find a different job and the intention to leave the position [39], [41].

The antecedents of turnover intention include leadership, occupational stress, organizational justice, work satisfaction and quality of work life [42], [43]. Besides, there is an indication that employees' perceived service quality has negative effect on turnover intention [44].

A study found that the antecedents of turnover intention are divided into 5 major categories. First, the individual level includes demography, human capital, motivation and professionalism. Second, the organizational level includes remuneration and benefits. Third, the job-related factors include job characteristics, job social support, job difficulties and job attractiveness. Fourth, the psychological level consists of job satisfaction, organizational commitment, tedium and perceived-job concern. Fifth, the environmental level consists of family and friends, perceived-job alternativeness and technological advancement [45].

\subsection{Organizational Context and Workplace Incivility}

Organizational context is closely related to various behaviors within the organization; one of which is incivility [16], [46], [47].

Workplace incivility is a complex phenomenon that research needs to be done to investigate workplace incivility in the organization. Victims have reported that incivility is manifested into jokes, harsh words, stereotypes and intrusive behaviors. Frequently, these behaviors cannot be easily identified as discrimination. Moreover, recent times have seen the aggravation of the behaviors leading to sexual harassment. This situation results in more difficult reasons for acting against the perpetrators at the organizational level [48].

Previous studies found that power dynamics based on position or hierarchy in the organization, perpetrators' intentions and lack of organizational policies not only significantly affect the emergence of workplace incivility, but also reduce the adverse consequences of exposure to incivility [49].

Perceived Organizational Support (POS) is one of the aspects of organizational context that plays an important role in the relationship between workplace incivility, emotional exhaustion and perceived-service performance [50].

Management philosophy serves as the direction for the management of an organization about a concept consisting of organizational beliefs and 
principles. Management philosophy helps provide vivid pictures of the goals and norms of the organization. The world's cross-cultural management philosophy (West, North, East and South) is divided into: rational management, entrepreneurial management, clan management, market-oriented management and educated versus experienced management [51]-[53].

Organizational culture is a mutual agreement of the organization about beliefs, symbols, rituals and myths that evolve over time. Organizational culture is built by the leader's behaviors, structure, routines, rules and norms that guide and limit behaviors [54], [55].

A study was once conducted based on five different levels of analysis: (a) within-person temporal effects, (b) between-person (personality and attitudes) factors, (c) interpersonal behaviors (perception and communication of emotion), (d) group level (leadership and teams) and (e) organizational level (culture and climate) at workplace interactions; one of which is incivility. The study revealed that culture and climate can abet incivility-based interactions [56].

However, research in the area of organizational context consisting of management philosophy and organizational culture has received little attention [22]. Therefore, based on previous studies, two hypotheses can be formulated:

H1a: management philosophy of organizational context negatively affects incivility.

H1b: organizational culture of organizational context negatively affects incivility.

\subsection{Workplace Incivility and Turnover Intention}

Previous studies have shown various results of the effect of workplace incivility on turnover intention. Moreover, studies have indicated that negative emotions (anger, fear and anxiety) appear more frequent when employees witness incivility committed by same-sex co-workers than by opposite-sex co-workers [57].

Previous studies suggest that there is a significant link between workplace incivility and outcomes such as stress, burnout, turnover intention, total years of work experience and education levels [58].

A study conducted in India revealed that incivility has a negative correlation with job satisfaction, but has a positive link with turnover intention [59].

Other studies have shown that co-workers' incivility is closely related with organizational outcomes such as job satisfaction, job performance and turnover intention [60], [61].

In regards to gender, some studies have indicated that workplace incivility tends to occur in women than in men. However, it does not explain who committed incivility. Women may become incivility perpetrators when men are the dominant members of the group, or women commit incivility to fellow women in the organization. The findings of a previous study revealed that female employees experienced workplace incivility from fellow female employees more frequent than from men. Female employees experiencing incivility triggered by fellow female employees result in turnover intention [62].

Another study demonstrated that incivility committed by co-workers, which is usually called coworker incivility, is positively related to outcomes, such as job insecurity and emotional exhaustion, in addition to turnover intention [63].

Based on the review of previous studies, a hypothesis is formulated:

H2: Incivility is positively related to turnover intention.

\subsection{Research Model}

Based on previous research, the research model describing the relationship between the research variables and hypotheses is presented below.

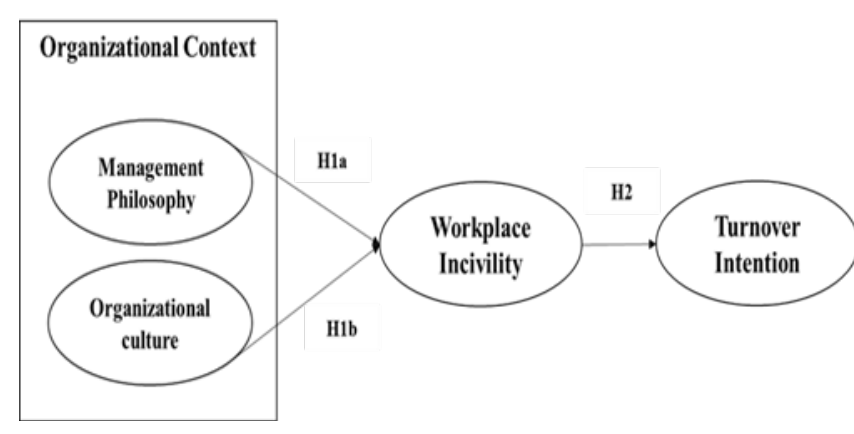

Fig. 1 Research Model

\section{RESEARCH METHOD}

\subsection{Population and Sample}

This is a cross-sectional study since it involved a particular phenomenon at a particular period of time to investigate the relationship between factors in an organization. Cross-sectional studies frequently employ survey strategy [64].

The unit of analysis of a study is an entity correlated to the focus of the research. The unit of analysis can be individuals, groups, organizations, objects and terms. Institutions or organizations on a large or small scale can become the unit of analysis 
[65]. The unit of analysis in this study are individuals at the government gas station which is one of the large organizations.

Population is a whole group of people, events or objects that are interesting to be studied and are used by the researchers to draw conclusions based on statistic samples [65]. The population of this study was all employees in a government gas station in Yogyakarta.

Sample is part of the population and involves procedures that can be utilized to draw conclusions based on the measurement of portions and population [66]Sample size can be obtained with 520 times the estimated number of parameters [67]. This study consisted of 24 parameters so that the number of samples was $5 \times 24=120$ samples or respondents.

The research instrument was a q uestionnaire measured using the 5-Likert scale in which scale 1 means completely disagree and 5 means completely agree. Research data was analyzed using multiple regression analysis.

\subsection{Regression Model}

This study uses multiple regression analysis to determine the effect of management philosophy and organizational culture on workplace incivility, and workplace incivility on turnover intention. Specifically, the following is a mathematical model for regression models is estimated:

Model 1: $\mathrm{WI}_{\mathrm{i}, \mathrm{t}}=\beta_{0}+\beta_{1} \mathrm{MP}_{\mathrm{i}, \mathrm{t}}+\beta_{2} \mathrm{OC}_{\mathrm{i}, \mathrm{t}}+\varepsilon_{\mathrm{i}, \mathrm{t}}$ Model 2: $\mathrm{TI}_{\mathrm{i}, \mathrm{t}}=\beta_{0}+\beta_{1} \mathrm{MP}_{\mathrm{i}, \mathrm{t}}+\beta_{2} \mathrm{OC}_{\mathrm{i}, \mathrm{t}}+\beta_{3} \mathrm{OC}_{\mathrm{i}, \mathrm{t}}+$ $\varepsilon_{\mathrm{i}, \mathrm{t}}$

Where WI: Workplace Incivility; MP: Management Philosophy; OC: Organizational Culture; TI: Turnover Intention.

\subsection{Variable Definition and Indicators}

Table 1 shows definitions and indicators used in this study.

Table 1 Variable Definition and Indicators

\begin{tabular}{|c|c|c|}
\hline No & Variables & Indicators \\
\hline \multirow[t]{7}{*}{1} & Management & items \\
\hline & Philosophy & statements \\
\hline & direction for the & management \\
\hline & management of an & philosophy \\
\hline & organization about a & eastern country \\
\hline & concept consisting of & setting adapted from \\
\hline & $\begin{array}{l}\text { beliefs } \\
\text { organizational and }\end{array}$ & $\begin{array}{l}\text { Bendixen \& Burger } \\
\text { [52]. }\end{array}$ \\
\hline
\end{tabular}

2 Organizational

Culture is a mutual agreement of the organization about beliefs, symbols, rituals and myths that evolve over time. Organizational culture is built by the leader's behaviors, structure, routines, rules and norms that guide and limit behaviors [54], [55].

3 Incivility is a d eviant 4 items of behavior with low statements adapted intensity and an from Sliter, Sliter \& ambiguous intention Jex [69].

to harm other employees and violate social norms to have mutual respect and politeness [38]

4 Turnover intention refers to the likelihood of someone leaving an organization at some time in the near future

8 items of statements divided into several dimensions: involvement, consistency, adaptability and mission, adapted from Denison \& Mishra [68]. [70].

\section{RESULTS AND DISCUSSION}

\subsection{Results}

Description of respondents showed their characteristics based on gender, educational background, age and working period. Results indicated that a total of $120 \mathrm{r}$ espondents were comprised of $80.5 \%$ of men and $19.5 \%$ of women $(19.5 \%)$.

In terms of education, the majority of respondents $(72 \%)$ had senior high school diploma; $3 \%$ had lower-than senior high school diploma; 20\% had an associate degree; and 5\% had a bachelor's degree.

Respondents came from different ages. The majority of respondents were 20-30 years of age $(60 \%) ; 30 \%$ of respondents were $31-40$ years of age; $6 \%$ were $41-50$ years of age; and $4 \%$ were 50 years of age and over.

Regarding working period, most of the respondents $(65 \%)$ had $0-5$ years of working period; 
$25 \%$ of the respondents had 6-10 years of working period; $7 \%$ had $10-15$ years; and 3\% had 15 years and over. Table 2 describes the validity and reliability of the measurement item of each variable. Based on the results of validity and reliability tests, it can be concluded that all items of this study were valid and reliable.

Table 2 Validity and Reliability Test

\begin{tabular}{|c|c|c|c|c|c|}
\hline \multirow{3}{*}{ Var } & \multirow{3}{*}{ Item } & \multirow{2}{*}{\multicolumn{2}{|c|}{$\begin{array}{c}\text { Validity } \\
\text { Test }\end{array}$}} & \multirow{2}{*}{\multicolumn{2}{|c|}{ Reliability Test }} \\
\hline & & & & & \\
\hline & & Correlations & Conc. & $\boldsymbol{\alpha}$ & Conc \\
\hline \multirow[t]{9}{*}{ MP } & 1 & 0.745 & Valid & 0.7189 & Reliable \\
\hline & 2 & 0.778 & Valid & & \\
\hline & 3 & 0.817 & Valid & & \\
\hline & 4 & 0.775 & Valid & & \\
\hline & 5 & 0.713 & Valid & & \\
\hline & 6 & 0.803 & Valid & & \\
\hline & 7 & 0.771 & Valid & & \\
\hline & 8 & 0.821 & Valid & & \\
\hline & 9 & 0.789 & Valid & & \\
\hline \multirow[t]{8}{*}{$\mathrm{OC}$} & 1 & 0.882 & Valid & 0.8118 & Reliable \\
\hline & 2 & 0.853 & Valid & & \\
\hline & 3 & 0.737 & Valid & & \\
\hline & 4 & 0.885 & Valid & & \\
\hline & 5 & 0.813 & Valid & & \\
\hline & 6 & 0.719 & Valid & & \\
\hline & 7 & 0.738 & Valid & & \\
\hline & 8 & 0.867 & Valid & & \\
\hline \multirow[t]{4}{*}{ WI } & 1 & 0.825 & Valid & 0.8257 & Reliable \\
\hline & 2 & 0.801 & Valid & & \\
\hline & 3 & 0.808 & Valid & & \\
\hline & 4 & 0.798 & Valid & & \\
\hline \multirow[t]{3}{*}{ TI } & 1 & 0.844 & Valid & 0.7983 & Reliable \\
\hline & 2 & 0.852 & Valid & & \\
\hline & 3 & 0.788 & Valid & & \\
\hline
\end{tabular}

* WI: Workplace Incivility; MP: Management Philosophy; OC: Organizational Culture; TI: Turnover Intention.

The results of regression analysis in this study indicated that the values of $\mathrm{R}^{2}$ and adjusted $\mathrm{R}^{2}$ were 0,788-799 for each variable.

The research variables consisted of the aspects of organizational context including management philosophy and organizational culture; the independent variable was workplace incivility; and the dependent variable was turnover intention.

Results of the study showed that the $\beta$ value ranged from 0.286 to 0.388 with the significance level $0.000-0.003$ for each variable. Results of regression analysis are presented in Table 3 . Hypotheses testing results indicated that all the proposed hypotheses were supported and ten presented in Table 4.
Table 3 Regression Analysis

\begin{tabular}{ccccccc}
\hline & I & $\mathbf{D}$ & $\boldsymbol{\beta}$ & Sig & $\mathbf{R}^{2}$ & $\begin{array}{c}\text { Adj. } \\
\mathbf{R}^{2}\end{array}$ \\
\hline 1 & MP & WI & $\begin{array}{c}- \\
0.397\end{array}$ & 0.000 & 0.715 & 0.626 \\
& & & - & 0.000 & 0.708 & 0.689 \\
& OC & WI & 0.467 & & & \\
2 & WI & TI & 0.286 & 0.003 & 0.778 & 0.714 \\
& MP & & 0.388 & 0.000 & 0.798 & 0.702 \\
& OC & & 0.379 & 0.002 & 0.799 & 0.734 \\
\hline
\end{tabular}

*I: Independent Var; D: Dependent Var; WI:

Workplace Incivility; MP: Management Philosophy;

OC: Organizational Culture; TI: Turnover Intention.

Table 4 Hypotheses Testing Result

\begin{tabular}{lcl}
\hline \multicolumn{1}{c}{ Hypotheses } & Sig. & Result \\
\hline $\mathrm{MilP} \rightarrow$ WI & 0.000 & Supported \\
$\mathrm{OC} \rightarrow$ WI & 0.000 & Supported \\
WI $\rightarrow$ TI & 0.003 & Supported \\
\hline WI: Workplace & Incivility; MP: & Management \\
Philosophy; OC: & Organizational & Culture; TI: \\
Turnover Intention. & &
\end{tabular}

\subsection{Discussion}

Organizational context in this study has two dimensions: management philosophy and organizational culture. Hypothesis 1a states that management philosophy is negatively related to workplace incivility. Hypothesis testing results suggest that management philosophy negatively and significantly affects workplace incivility. This result means that if employees have good management philosophy and implement it at the workplace daily, workplace incivility can be lowered.

Hypothesis $1 \mathrm{~b} \mathrm{~s}$ tates that organizational culture is negatively related to workplace incivility. Hypothesis testing results suggest that organizational culture negatively and significantly affects workplace incivility. This result signifies that organizational culture if effectively internalized in the organization can prevent workplace incivility.

The results of this study are consistent with the results of previous studies. Two studies were conducted to find the effects of organizational context based on the work characteristics of organization, including individualism, hostile interaction styles, competition, hierarchical governance and email reliance, on workplace incivility. The results showed that email reliance is correlated with workplace incivility and workplace incivility can predict negative work outcomes such 
as turnover intention, job satisfaction and physical health [16].

Another study found that organizational aspects such as organizational change, job insecurity, low social support from co-workers and high job demands have a link with workplace incivility. It also found that organizational aspects can reflect the climate and culture of an organization and the incivility process [46].

It is important for a study on workplace incivility to focus on organizational context in order to identify the causes and design policies to combat with workplace incivility. Organizational context can include bureaucracy, organizational chaos and racial composition. A study found that those three aspects of organizational context are influential on workplace incivility [47].

A study gave empirical evidence that organizational context comprised of management philosophy and organizational culture contributes to workplace incivility [22].

Workplace incivility is found to influence various work outcomes; one of which is turnover intention. Hypothesis 2 states that workplace incivility has a positive impact on workplace incivility. Hypothesis testing results suggest that workplace incivility is positively and significantly related to turnover intention. This result signifies that workplace incivility can increase employees' turnover intention. This result corresponds to other studies that found that workplace incivility influences turnover intention [57], [59], [61], [63].

Workplace incivility is often considered the primary source of job dissatisfaction. Incivility contributes to the high level of turnover intention, especially on new employees [71]. New employees need longer time to adapt with the work environment. The initial years of work play an important part in the employees' desire to stay in the organization. The work environment that tolerates workplace incivility is highly likely to cause turnover intention among employees who are later attempting to find better jobs or organizations.

Ignoring turnover intention for a longer period of time will lead to employees' attitude to leave the workplace or current job. This situation requires an adoption of a proactive approach to deal with employees who have experienced incivility and to prevent incivility in the future [72].

Results of another study demonstrated that workplace incivility negatively affects job satisfaction, but positively affects turnover intention. The results illustrate a situation that when an employee is experiencing workplace incivility and job dissatisfaction, he/she will experience turnover intention. Organizations or companies are expected to give serious attention to and proper handling of workplace incivility since it can result in employees' turnover intention [73].

Workplace incivility is a behavior that deviates mutual respect and ethics at work [4]. Previous studies found that ethical efficacy and perceived workplace incivility affect turnover intention [74].

\section{Conclusion}

There is a growing body of research on the antecedents and workplace incivility outcomes under the concept of behavior science. The banking and financial engineering sector is part of the service industry related to ethical practices in serving behavior. Management philosophy and organizational culture applied in an organization will help shape the ethics, values, norms and behavior of employees and leaders. Almost every organization believes that the principle of running a good business is ethical. Ethics can be used as a standard or guideline for all employees to make it as a guide in working. Behavior that maintains ethics can be in the form of mutual respect and behaves civility or does not behave workplace incivility.

This study is useful to explain the role of organizations in influencing behavior among employees. The organization should not only have a philosophy and culture that is clearly stated, but the values contained can be internalized in each employee. The values of management philosophy and organizational culture can form positive work behavior which will later be beneficial in forming a pleasant and friendly work environment. This study is also useful for managers and decision makers in organizations to recognize subtle deviant behaviors such as incivility. However, there is a need to enrich the research in this domain to discover various factors of workplace incivility at the individual, group, and organizational levels.

This research generated empirical evidence for assessment in the aspects of organizational context, management philosophy and organizational culture. Previous researches in organizational context have shown that it has effects on workplace incivility. Thus, this research shows a co nsistent result with them.

The consequence of workplace incivility affects various outcomes individually or organizationally. 
This research shows that workplace incivility can increase turnover intention.

There are some practical implications of this research; one of which is the importance of creating strategy and regulation for the sake of employee's retention. The organization and its executive should be aware of the needs and interests of the employee who has $\mathrm{a} b$ ig risk to leave the company. In addition, organization should encourage coworkers and employers to give more support to employees who experience workplace incivility.

This study also includes some suggestions for future research. First, small attention has been given to research on incivility outcomes on individual

\section{References:}

[1] S. H. Appelbaum, G. D. Iaconi, and A. Matousek, "Positive and negative deviant workplace behaviors: Causes, impacts, and solutions," Corp. Gov., 2007.

[2] D. W. Osgood, J. K. Wilson, P. M. O'Malley, J. G. Bachman, and L. D. Johnston, "Routine activities and individual deviant behavior," Am. Sociol. Rev., 1996.

[3] C. Roberson and E. Azaola, Deviant behavior. 2015.

[4] L. M. Andersson and C. M. Pearson, "Tit for tat? the spiraling effect of incivility in the workplace," Acad. Manag. Rev., vol. 24, no. 3, pp. 452-471, 1999.

[5] Christine Porath, "The hidden toll of workplace incivility," McKinsey Q., 2016.

[6] C. M. Pearson and C. L. Porath, "On the nature, consequences and remedies of workplace incivility: No time for 'nice'? Think again," Acad. Manag. Perspect., vol. 19, no. 1, pp. 7-18, 2011.

[7] G. W. Giumetti, E. S. McKibben, A. L. Hatfield, A. N. Schroeder, and R. M. Kowalski, "Cyber incivility@ @ork: The new age of interpersonal deviance," Cyberpsychology, Behav. Soc. Netw., 2012.

[8] S. A. Hutton, "Workplace incivility: State of the science," Journal of Nursing Administration, vol. 36, no. 1.pp. 22-27, 2006.

[9] I. M. Jawahar and B. Schreurs, "Supervisor incivility and how it affects subordinates' performance: a matter of trust," Pers. Rev., 2018.

[10] V. K. G. Lim, T. S. H. Teo, and R. Nishant, "Cyber Incivility at the Workplace," in ICIS 2017: Transforming Society with Digital health. Previous studies mostly focused on the impacts of workplace incivility on ps ychological health. Second, future research should consider an investigation on types of behaviors of workplace incivility since previous studies mainly centered around workplace incivility on the aspects of perpetrators, witnessed and victims. This is necessary to be done in order to enrich studies in the area of workplace incivility. Third, future research should examine factors that can strengthen or weaken workplace incivility on the outcomes using moderation variables.

Innovation, 2018.

[11] A. M. Patterson, A. C. Chris, and M. G. González-Morales, "Workplace incivility," in The Routledge Companion to Wellbeing at Work, 2018, pp. 150-168.

[12] S. A. Vagharseyyedin, "Workplace incivility: A concept analysis," Contemp. Nurse, 2015.

[13] D. D. van Jaarsveld, D. D. Walker, and D. P. Skarlicki, "The role of job demands and emotional exhaustion in the relationship between customer and employee incivility," J. Manage., 2010.

[14] Z. E. Zhou, L. L. Meier, and P. E. Spector, "The spillover effects of coworker, supervisor, and outsider workplace incivility on work-to-family conflict: A weekly diary design," J. Organ. Behav., 2019.

[15] P. Andersen, M. McAllister, S. KardongEdgren, C. W. Miller, and C. Churchouse, "Incivility behaviours exhibited by nursing students: clinical educators' perspectives of challenging teaching and assessment events in clinical practice," Contemp. Nurse, 2019.

[16] K. N. Miner, A. L. Smittick, Y. He, and P. L. Costa, "Organizations Behaving Badly: Antecedents and Consequences of Uncivil Workplace Environments," J. Psychol. Interdiscip. Appl., 2019.

[17] G. Thompson, R. Buch, and L. Glasø, "Lowquality LMX relationships, leader incivility, and follower responses," J. Gen. Manag., 2018.

[18] J. S. Bureau, M. Gagné, A. J. S. Morin, and G. A. Mageau, "Transformational Leadership and Incivility: A Multilevel and Longitudinal Test," J. Interpers. Violence, 2017.

[19] K. A. Arnold and M. M. Walsh, "Customer incivility and employee well-being: testing 
the moderating effects of meaning, perspective taking and transformational leadership," Work Stress, 2015.

[20] J. A. Kaiser, "The relationship between leadership style and nurse-to-nurse incivility: turning the lens inward," J. Nurs. Manag., 2017.

[21] H. T. T. Suong, "The impacts of transformational leadership on motivation of employees: The case of employees at vietnamese small and medium enterprises," WSEAS Trans. Bus. Econ., 2020.

[22] B. Estes and J. Wang, "Integrative literature review: Workplace incivility: Impacts on individual and organizational performance," Human Resource Development Review, vol. 7, no. 2. pp. 218-240, 2008.

[23] J. Samosh, "What is Workplace Incivility? An Investigation of Employee Relational Schemas," Organ. Manag. J., vol. 16, no. 2, pp. 81-97, 2019.

[24] N. M. S. Aljawarneh and T. Atan, "Linking Tolerance to Workplace Incivility, Service Innovative, Knowledge Hiding, and Job Search Behavior: The Mediating Role of Employee Cynicism," Negot. Confl. Manag. Res., 2018.

[25] Q. Bai, W. Lin, and L. Wang, "Family incivility and counterproductive work behavior: A moderated mediation model of self-esteem and emotional regulation," $J$. Vocat. Behav., 2016.

[26] L. Beattie and B. Griffin, "Day-level fluctuations in stress and engagement in response to workplace incivility: A diary study," Work Stress, 2014.

[27] Y. Shi et al., "Impact of workplace incivility against new nurses on job burn-out: A crosssectional study in China," BMJ Open, 2018.

[28] O. Smidt, L. T. de Beer, L. Brink, and M. P. Leiter, "The validation of a workplace incivility scale within the South African banking industry," SA J. Ind. Psychol., 2016.

[29] V. J. Roscigno, R. Hodson, and S. H. Lopez, "Workplace incivilities: The role of interest conflicts, social closure and organizational chaos," Work. Employ. Soc., vol. 23, no. 4, pp. 747-773, 2009.

[30] K. Holm, E. Torkelson, and M. Bäckström, "Models of Workplace Incivility: The Relationships to Instigated Incivility and Negative Outcomes," Biomed Res. Int., vol. 2015, pp. 1-10, 2015.

[31] S. Clinebell and G. Shadwick, "The Importance of Organizational Context on
Employees' Attitudes: An Examination of Worlking in Main Offices Versus Branch Offices,” J. Leadersh. Organ. Stud., 2005.

[32] M. A. Griffin, "Specifying organizational contexts: Systematic links between contexts and processes in organizational behavior," Journal of Organizational Behavior. 2007.

[33] D. M. Rousseau, "Characteristics of Departments, Positions, and Individuals: Contexts for Attitudes and Behavior," Adm. Sci. Q., 1978.

[34] T. L. Doolen, M. E. Hacker, and E. M. Van Aken, "The impact of organizational context on work team effectiveness: A study of production team," IEEE Trans. Eng. Manag., 2003.

[35] G. Rusu, S. Avasilcăi, and C.-A. Huţu, "Organizational Context Factors Influencing Employee Performance Appraisal: A Research Framework," Procedia - Soc. Behav. Sci., 2016.

[36] M. Ferguson, "You cannot leave it at the office: Spillover and crossover of coworker incivility," J. Organ. Behav., 2012.

[37] J. Trudel and T. G. Reio, "Managing workplace incivility: The role of conflict management styles-antecedent or antidote?," Hum. Resour. Dev. Q., vol. 22, no. 4, pp. 395-423, 2011.

[38] K. Sakurai and S. M. Jex, "Coworker incivility and incivility targets' work effort and counterproductive work behaviors: The moderating role of supervisor social support," J. Occup. Health Psychol., 2012.

[39] W. Rahman and Z. Nas, "Employee development and turnover intention: Theory validation," Eur. J. Train. Dev., 2013.

[40] R. P. Tett and J. P. Meyer, "Job Satisfaction, Organizational Commitment, Turnover Intention, And Turnover: Path Analyses Based On Meta-Analytic Findings," Pers. Psychol., 1993.

[41] A. Carmeli and J. Weisberg, "Exploring turnover intentions among three professional groups of employees," Hum. Resour. Dev. Int., 2006.

[42] B. Kaur, "Antecedents of Turnover Intentions: A Literature Review," Glob. J. Manag. Bus. Stud., 2013.

[43] J. E. Wells and J. Welty Peachey, "Turnover intentions," Team Perform. Manag. An Int. J., 2011.

[44] T. Slåtten, G. Svensson, and S. Sværi, "Service quality and turnover intentions as perceived by employees: Antecedents and 
consequences," Pers. Rev., vol. 40, no. 2, pp. 205-221, 2011.

[45] A. H. Ghapanchi and A. Aurum, "Antecedents to IT personnel's intentions to leave: A systematic literature review," $J$. Syst. Softw., 2011.

[46] E. Torkelson, K. Holm, and M. Bäckström, "Workplace Incivility in a Swedish Context," Nord. J. Work. Life Stud., vol. 6, no. 2, p. 3, 2016.

[47] L. M. Williams, "Three essays on organizational context and incivility in schools and workplaces," 2014.

[48] D. Di Marco, H. Hoel, A. Arenas, and L. Munduate, "Workplace Incivility as Modern Sexual Prejudice," J. Interpers. Violence, 2018.

[49] P. V Doshy and J. Wang, "Workplace Incivility: What Do Targets Say About It?," Am. J. Manag., 2014.

[50] S. J. Han, M. A. Bonn, and M. Cho, "The relationship between customer incivility, restaurant frontline service employee burnout and turnover intention," Int. J. Hosp. Manag., 2016.

[51] F. Analoui and A. Karami, "CEOs and development of the meaningful mission statement," Corp. Gov. Int. J. Bus. Soc., 2002.

[52] M. Bendixen and B. Burger, "Cross-cultural management philosophies," J. Bus. Res., 1998.

[53] Y. Wang, "Mission-Driven Organizations in Japan: Management Philosophy and Individual Outcomes," J. Bus. Ethics, 2011.

[54] S. R. Glaser, S. Zamanou, and K. Hacker, "Measuring and interpreting organizational culture," Manag. Commun. Q., 1987.

[55] E. H. Schein, "Organizational Culture and Leadership, Third Edition," Publ. by JosseyBass, 2004.

[56] N. M. Ashkanasy and A. D. Dorris, "Emotions in the Workplace," Annu. Rev. Organ. Psychol. Organ. Behav., 2017.

[57] K. N. Miner and A. Eischeid, "Observing Incivility toward Coworkers and Negative Emotions: Do Gender of the Target and Observer Matter?," Sex Roles, 2012.

[58] O. Oyeleye, P. Hanson, N. O'Connor, and D. Dunn, "Relationship of workplace incivility, stress, and burnout on nur ses' turnover intentions and psychological empowerment," J. Nurs. Adm., 2013.

[59] N. Sharma and V. K. Singh, "Effect of workplace incivility on job satisfaction and turnover intentions in India," South Asian J. Glob. Bus. Res., 2016.

[60] R. Ghosh, T. G. Reio, and H. Bang, "Reducing turnover intent: Supervisor and co-worker incivility and socialization-related learning," Hum. Resour. Dev. Int., 2013.

[61] S. Y. Rhee, W. M. Hur, and M. Kim, "The Relationship of Coworker Incivility to Job Performance and the Moderating Role of Self-Efficacy and Compassion at Work: The Job Demands-Resources (JD-R) Approach," J. Bus. Psychol., 2017.

[62] A. S. Gabriel, M. M. Butts, Z. Yuan, R. L. Rosen, and M. T. Sliter, "Further understanding incivility in the workplace: The effects of gender, agency, and communion," J. Appl. Psychol., 2018.

[63] Y. Shin and W.-M. Hur, "When Do Service Employees Suffer More from Job Insecurity? The Moderating Role of Coworker and Customer Incivility," Int. J. Environ. Res. Public Health, vol. 16, no. 7, p. 1298, A pr. 2019.

[64] M. N. K. Saunders, P. Lewis, and A. Thornhill, "Research methods for business students," in Research Methods for Business Students (Seventh Edition), 2016, p. 741.

[65] U. Sekaran and R. Bougie, Business Research Methods: A skill-building approach. 2011.

[66] Zikmund, Babin, Carr, and Griffin, "Sampling Designs and Sampling Procedures," Bus. Res. Methods, pp. $386-$ 411, 2009.

[67] R. B. Kline, Principles and practice of structural equation modelling (4th ed.). 2015.

[68] D. R. Denison and A. K. Mishra, "Toward a Theory of Organizational Culture and Effectiveness," Organ. Sci., 1995.

[69] M. Sliter, K. Sliter, and S. Jex, "The employee as a punching bag: The effect of multiple sources of incivility on employee withdrawal behavior and sales performance," J. Organ. Behav., vol. 33, no. 1, pp. 121139, 2012.

[70] M. F. Chen, C. P. Lin, and G. Y. Lien, "Modelling job stress as a mediating role in predicting turnover intention," Serv. Ind. J., 2011.

[71] A. M. D'Ambra and D. R. Andrews, "Incivility, retention and new graduate nurses: An integrated review of the literature," J. Nurs. Manag., vol. 22, no. 6, pp. 735-742, 2014. 
[72] T. Nazir and U. N. Ungku, "Interrelationship of incivility, cynicism and turnover intention," Int. Rev. Manag. Mark., vol. 6, no. 1, pp. 146-154, 2016.

[73] H. T. Chen and C. H. Wang, "Incivility, satisfaction and turnover intention of tourist hotel chefs: Moderating effects of emotional intelligence," Int. J. Contemp. Hosp. Manag., vol. 31, no. 5, pp. 2034-2053, 2019.

[74] H. T. Huang and C. P. Lin, "Assessing ethical efficacy, workplace incivility, and turnover intention: a moderated-mediation model," Rev. Manag. Sci., vol. 13, no. 1, pp. 33-56, 2019. 